In-Patient Psychiatric Settings and Emergency Departments. London: National Institute of Clinical Excellence.

Stewart, I., Knight, C. and Johnson, C. (2008). Just how challenging can older people be? Part 2: Making the case for specialist services for risky and aggressive behavior. PSIGE Nerwsletter, 103, 66-74.

Stubbs, B. (2010). Physiotherapist involvement and views on the application of physical intervention to manage aggression: data from a national survey. Fournal of Psychiatric and Mental Health Nursing, 17, 754-756.

Stubbs, B., Yorston, G. and Knight, C. (2008) Physical intervention to manage aggression in older adults: how often is it employed? International Psychogeriatrics, 20, 855-857.

doi:10.1017/S1041610210001912

\section{Rehabilitation for dementia using enjoyable video-sports games}

The aging of society inevitably leads to an increase in the numbers of elderly with dementia who reside in nursing homes, and delaying disease progression of residents with dementia has become a big concern. Rehabilitation that focuses directly on training cognitive function (e.g. memory training) reveals what patients are unable to do. Realization of their cognitive deficits can devastate their selfconfidence and lead to anxiety, depression and the lowering of self-esteem (Small et al., 1997). We propose rehabilitation that encourages patients' motivation for self-improvement through social interaction based on five principles as follows: (1) the activities should be enjoyable and comfortable for patients, (2) therapists should praise the patients naturally to motivate them, (3) the activities should be associated with empathetic two-way communication to make patients feel valued and safe, (4) therapists should encourage the patients to play "social roles" to restore self-worth, and (5) error-less learning based on brain-activating rehabilitation (BAR; Yamaguchi et al., in press) should be adopted wherever possible. It is suggested that the positive feelings activate those areas of the brain related to reward, which plays a critical role in motivation (Berridge et al., 2003), and it is a typical social reward to be praised and appreciated in public.

Based on BAR, we tried to improve residents' cognitive function indirectly by enhancing motivation using enjoyable video-sports games in a group setting. We conducted interventions with nine elderly people with mild to moderate dementia $(88.9 \pm 4.9$ years of age, mean $\pm S D$; three males and six females: one with Parkinson's disease dementia, one with vascular dementia, and seven
Winstanley, S. and Whittington, R. (2004). Aggressive encounters between patient and healthcare staff: the context and assailants levels of cognitive processing. Aggressive Behaviour, 30, 534-543.

\author{
BRENDON STUbBs ${ }^{1}$ AND LeE Hollins ${ }^{2}$ \\ ${ }^{1}$ Clinical Specialist Mental Health Research \\ Physiotherapist, Northampton, U.K. \\ Email: brendonstubbs@hotmail.com \\ ${ }^{2}$ Physiotherapist and Physical Intervention Tutor, \\ London, U.K.
}

with Alzheimer's disease (AD)) residing in a nursing home. All were in the stable phase of dementia, and had been admitted to the nursing home at least three months previously. None of the participants was medicated with donepezil hydrochloride.

We used video sports-games specifically devised for rehabilitation (Hot-plus, SSD Co. Ltd, Shiga Japan). These utilize psychomotor skills, such as hand-eye coordination, require timing, and necessitate fine three-dimensional control of the limbs in space. There were essentially two types of games: those working the upper limbs, and those the lower limbs. An example of the games for upper limbs required a player to grab coins which appeared to be coming out of the TV screen. The players wore bands on their hands equipped with sensors, and when the timing and direction were accurate, they scored points. Games for the lower limbs included those which required the players to move their legs to music. Two Japanese drums were shown on the TV screen, and two balls fell slowly from the top of the TV screen. A player was required to tap his/her feet on a mat equipped with sensors, synchronizing with the balls bouncing on the drums. $\mathrm{He} / \mathrm{she}$ scored when the timing was accurate. These interventions were conducted once a week for ten weeks.

General cognitive function was measured using Hasegawa's Dementia Scale-revised (HDS-R), which is similar and well-correlated with the Minimental State Examination. The visuospatial and constructive function was measured using Kohs block-design tests (Kohs). Behavioral changes were evaluated using the Multidimensional Observation Scale for Elderly Subjects (MOSES), with the subitems of self-care, disorientation, depression, irritability, and withdrawal. No residents had previously experienced playing the video-sports games and so to help the residents enjoy the games, the caregivers (aged $40.8 \pm 12.9$ years, 7 males and 
Table 1. The HDS-R, Kohs and MOSES scores

\begin{tabular}{|c|c|c|c|}
\hline SCALE & $\begin{array}{l}\text { BASELINE } \\
(M E A N \pm S D)\end{array}$ & $\begin{array}{l}\text { POST- } \\
\text { INTERVENTION } \\
(M E A N \pm S D)\end{array}$ & $\begin{array}{l}\text { PAIRED-T } \\
\text { TEST }(p)\end{array}$ \\
\hline HDS-R & $18.89 \pm 4.26$ & $25.33 \pm 2.35$ & 0.002 \\
\hline Kohs & $20.22 \pm 15.62$ & $37.44 \pm 12.44$ & 0.02 \\
\hline \multicolumn{4}{|l|}{ MOSES } \\
\hline Self-care & $15.18 \pm 4.09$ & $15.00 \pm 3.74$ & 0.92 \\
\hline Disorientation & $12.01 \pm 2.47$ & $10.64 \pm 2.06$ & 0.15 \\
\hline Depression & $12.36 \pm 3.08$ & $10.46 \pm 2.58$ & 0.13 \\
\hline Irritability & $9.46 \pm 0.82$ & $9.00 \pm 0.63$ & 0.16 \\
\hline Withdrawal & $15.09 \pm 5.13$ & $13.55 \pm 4.53$ & 0.46 \\
\hline Total & $64.18 \pm 7.29$ & $58.64 \pm 5.16$ & 0.054 \\
\hline
\end{tabular}

12 females) participated in the sessions. They were taught in advance how to maintain empathetic twoway communication with the elderly participants. They were given a communication checklist of 34 items before commencement, and they kept an observation record to reinforce empathetic communication with residents.

The HDS-R scores improved from $18.98 \pm$ 4.26 (mean $\pm \mathrm{SD}$ ) to $25.33 \pm 2.35(p=0.002$, paired t-test), the Kohs test scores improved from $20.22 \pm 15.62$ to $37.44 \pm 12.44 \quad(p=0.02)$, and the total MOSES scores improved from $64.18 \pm 7.29$ to $58.64 \pm 5.16(p=0.054$; Table 1$)$. Regarding communication, the sociability of residents also showed an improvement as seen in the MOSES subitems relating to communication and social interaction - i.e. depression, irritability, and withdrawal. According to the caregivers' observation records, the residents' faces became expressive, especially with smiles. Caregivers' communication skills were also improved by selfassessment $(12.92 \pm 2.07$ items in the checklists with 34 items listed before commencement of the sessions). Communication was not limited to verbal communication; the main purpose of communication was to enjoy exchanges of affection and empathy rather than to obtain information; thus, nonverbal communication was very important. With the aid of the games, a situation promoting communication could be easily created by playing doubles, watching others play, cheering each other on, etc.

Although it is not possible to prove a causal relationship between cognitive improvement and increased communication, a community-based study has shown that communication, i.e. social interaction in the broad sense, has a protective effect in preserving mental function in the elderly (Wang et al., 2002). Furthermore, communication might at least help ameliorate the residents' disuse syndrome. Disuse syndrome keeps the residents below the mental level expected based on the degree of brain pathology or brain damage. Nursing home residents tend to be passive, apathetic and dependent on caregivers. According to a survey conducted in Japan to explore the characteristics of depressive mood in different care settings, the residents in nursing homes felt more dissatisfied, apathetic and worthless, and unwilling to stay there, compared with community-dwelling residents and the hospitalized elderly (Onishi et al., 2006). A depressive and apathetic tendency leads to cognitive and functional decline in $\mathrm{AD}$; the results of MOSES showed some sign of improvement with regard to depressive tendencies. The cognitive decline resulting from disuse may be a reversible change, and so residents may regain their capacities.

Inter-subjectivity is a major factor in the rehabilitation for dementia; playing video-sports games in a group setting can be effective in improving the cognitive function of elderly people with dementia, especially when performed with trained caregivers who understand the principles of BAR: namely, the importance of creating enjoyment, empathetic two-way communication, using praise, and developing social roles.

\section{Conflict of interest}

None.

\section{Description of authors' roles}

Y. Maki and H. Yamaguchi formulated the research question, designed the study, carried it out, analyzed the data and wrote the letter. K. Takahashi was the doctor in charge of the patients. 


\section{Acknowledgments}

This research was supported by a Grant-in-Aid for Scientific Research from the Ministry of Education, Science, Sports, Culture and Technology, Japan (18650196) and a Research Grant for Longevity Sciences (21A-12) from the Ministry of Health, Labor and Welfare. The authors thank the residents and care staff of Seseragi-en nursing home, R. Shinohara and Y. Tsunoda.

\section{References}

Berridge, K. C. (2002). Pleasures of the brain. Brain and Cognition, 52, 106-128.

Onishi, J., Suzuki, Y., Umegaki, H., Endo, H., Kawamura, T. and Iguchi, A. (2006). A comparison of depressive mood of older adults in a community, nursing homes, and a geriatric hospital: factor analysis of Geriatric Depression Scale. Fournal of Geriatric Psychiatry and Neurology, 19, 26-31.
Small, G. W. et al. (1997). Diagnosis and treatment of Alzheimer disease and related disorders: Consensus Statement of the American Association for Geriatric Psychiatry, the Alzheimer's Association and the American Geriatrics Society. FAMA, 278, 1363-1371.

Wang, H. X., Karp, A., Winblad, B. and Fratiglioni, L. (2002). Late-life engagement in social and leisure activities is associated with a decreased risk of dementia: a longitudinal study from the Kungsholmen Project. American fournal of Epidemiology, 155, 1081-1087.

Yamaguchi, H., Maki, Y. and Yamagami, T. (in press). Overview of nonpharmacological intervention for dementia and principles of brain-activating rehabilitation. Psychogeriatrics: Official fournal of the Fapanese Psychogeriatric Society.

H. YAMAGUCHI, ${ }^{1}$ Y. MAKI ${ }^{1,2}$ AND

K. TAKAHASHI ${ }^{3}$

${ }^{1}$ Gunma University School of Health Sciences, Maebashi, Japan

${ }^{2}$ Department of Neurology, Geriatrics Research Institute and Hospital, Maebashi, Japan

${ }^{3}$ Matsuida Hospital, Annaka, Japan Email: yamaguti@health.gunma-u.ac.jp. 